\title{
INTERSUBJECTIFICATION IN COGNITIVE GRAMMAR: REFLECTING ON ENGLISH AND POLISH REFLEXIVES
}

Keywords: reflexivization, intersubjectification, reference point relationship, accessibility hierarchy, detransitivization

\begin{abstract}
The paper provides a cognitive grammar analysis of reflexivization phenomena in English and Polish. Three separate although related claims are made: (i) underlying reflexivization phenomena is the intersubjectification process which involves the so-called reference point relationship; (ii) the intersubjectification process takes place in the Current Discourse Space - CDS (Langacker 2008), whereby the degree of the antecedent's accessibility for the reflexive pronoun is established; (iii) while in Polish, the antecedent's accessibility is closely linked to the detransitivization process, in English, it is determined by the accessibility hierarchy in the sense of Kuno (1987).
\end{abstract}

\section{Reflexives in English and in Polish. Basic facts}

Generally, two types of reflexives have been distinguished in English: the reflexiveself as in the examples in (1) through (5), and the emphatic -self as in (6) through (8): ${ }^{1}$

(1) a. John saw himself in the mirror.

*b. Himself saw John in the mirror.

(2) John bought himself a nice jacket yesterday.

1 We will have nothing to say about the so-called reciprocal reflexive each other, which requires an antecedent in the plural, whose distribution is governed by the clause-mate condition (cf. note 2); nor shall we examine its Polish equivalent, jeden drugiego, found in sentences such as I wtedy jeden chtopiec uderzył drugiego 'And then one boy hit the other'. The Polish 
(3) John told Greg a story about himself.

(4) John believes S[himself to be a genius].

(5) *John believes $\mathrm{S}$ [that himself is a genius].

(6) a. John bought Mary a bunch of flowers himself.

b. Himself, John bought Mary a bunch of flowers.

c. ?John himself bought himself a nice jacket yesterday.

d. John himself believes S[that Mary is a genius].

(7) All my family, including myself, went to the seaside.

(8) A picture of himself that hangs in the gym hall seems to appear to amuse John.

The ungrammatical sentences in (1b) and (5) show that a reflexive-self may neither precede its antecedent (here John) as in (1b), nor can it appear in a clause other than its antecedent, as documented by $(5) .{ }^{2}$ Also, as illustrated by (3), a reflexive can co-refer with either the subject or the object of a sentence. In contrast, an emphatic-self seems to appear practically in all places in a sentence as (6) through (8) clearly show. ${ }^{3}$

Turning to Polish, one can distinguish three kinds of reflexives: (i) the casemarked siebie reflexive in the object, as illustrated in (9), (10), (11), (12) and (13), (ii) the clitic sie, which, generally, replaces the siebie form, as in (14), and appears in a number of się-forms such as impersonal constructions as in (15), (16) and (17), middle voice constructions (cf. (18)) and ergative forms (cf. (19)) ${ }^{4}$ and (iii) the case- and gender-marked emphatic sam, as in (20) and (21):

reciprocal form is not formally a reflexive. Still, treating, as we do, reciprocity in Polish as a semantic/conceptual category; we will discuss it in the context of the detransitivization process as signaled by the Polish reflexive siebie/się.

2 The example in (5) thus violates the so-called clause mate condition: myself is in the embedded clause, while its antecedent, John, appears in the main clause. The example in (4), however, is problematic: although myself and John are in two separate clauses, the sentence is grammatical. To salvage the clause mate condition the so-called subject raising rule-to-object was proposed in the generative literature, which moved myself, the subject of the embedded clause, to the object position of the main clause (hence the name of the rule, cf. Postal 1974). Chomsky (1973) rejected this solution. On his analysis the ungrammaticality of (5) was attributed to the fact that, in contradistinction to (4), the reflexive in (5) appears in a tensed clause (i.e. a clause that contains a finite form of the verb) and thus violates the so-called Tensed-S-Condition.

3 The sentence in (8) contains a picture noun, i.e. a nominal phrase such as a picture of himself, a film about herself, a novel about ourselves, etc. (cf. Warshawsky-Harris 1965; Jackendoff 1972). Because picture nouns, just like emphatics-self, seem to violate all conditions on reflexivization in that they can precede their antecedents and appear in clauses other than their antecedents (i.e. they violate the clause-mate condition), they have been treated as emphatics themselves (cf. Helke 1971; Leskosky 1972; Verheijen 1983; also Kardela 1985). For an in-depth analysis of reflexives in the generative grammar framework, see, for instance, Postal (1971) and Jackendoff (1972); for an extensive treatment of reflexives in Polish, see Wilczewska (1966), Szlifersztejnowa (1968), Kański (1986), Kubiński (1987), Szymańska (2000), Drogosz (2008), inter alia.

4 Ergative verbs can be used both intransitively, as illustrated by (19), or transitively, as in a sentence such as Jan zagotowat wodę 'John boiled the water'. 
(9) Marek zobaczył siebie w lustrze.

Mark saw himself-Acc. in the mirror.

(10) Piotr kupił sobie płaszcz.

Peter bought himself-Dat. a coat.

(11) Jan dużo mówił Marysi o sobie.

John told Mary a lot about himself/*herself.

(12) Jan obiecał Marysi S[- kupić sobie książkę o sztuce etruskiej].

John promised Mary to buy himself/*herself a book on Etruscan art.

(13) Ola kazała Janowi S[- kupić sobie płaszcz].

Ola asked John S[- to buy himself/herself a coat].

(14) Marek już umył się i ogolił.

Mark has just washed and shaved himself.

(15) Tu się dużo czyta i pisze.

One reads-refl. and writes a lot here.

(16) Nie odrobiło się pracy domowej, co?

One not has done-refl. his homework, eh?

(17) Bawiono się całą noc.

One/they were partying się-refl. all night.

(18) Te telewizory bardzo dobrze się sprzedają.

These TV-sets sell się-refl. very well.

(19) Woda właśnie się zagotowała.

The water się-refl. has just boiled.

(20) Grzegorz nakręcił ten film sam.

Greg has shot this film all by himself/alone.

(21) Sam Piotr niewiele o sobie mówi.

Lit. Sam-emph. Peter speaks very little about himself.

Peter himself speaks very little about himself.

Generally, reflexives in Polish are subject bound, as indicated by (11) and (12), where the reflexive sobie co-refers only with the subject Jan, not with the object Mary. However, when a reflexive appears in infinitive clauses with object controlled main clause verbs such as kazać 'ask (sb to do sth), tell (sb to do sth)', as in (13), the reflexive can be either subject- or object-bound. Also observe that, similar to the English usage, cf. (6c), the emphatic sam in Polish can appear together with a regular reflexive, as shown in (21).

\section{Reflexives as reference-point phenomena}

In Langacker's theory reflexives are treated as reference point phenomena, along with personal pronouns, possessives and the so-called raising constructions. The general reference point configuration for the pronoun-antecedent configuration looks as follows (Langacker 2000: 238): 


$$
\begin{array}{ll}
\mathrm{R}=\text { reference point (antecedent) } & \mathrm{T}=\text { target (pronoun) } \\
\mathrm{D}=\text { dominion } & \mathrm{C}=\text { conceptualizer }
\end{array}
$$

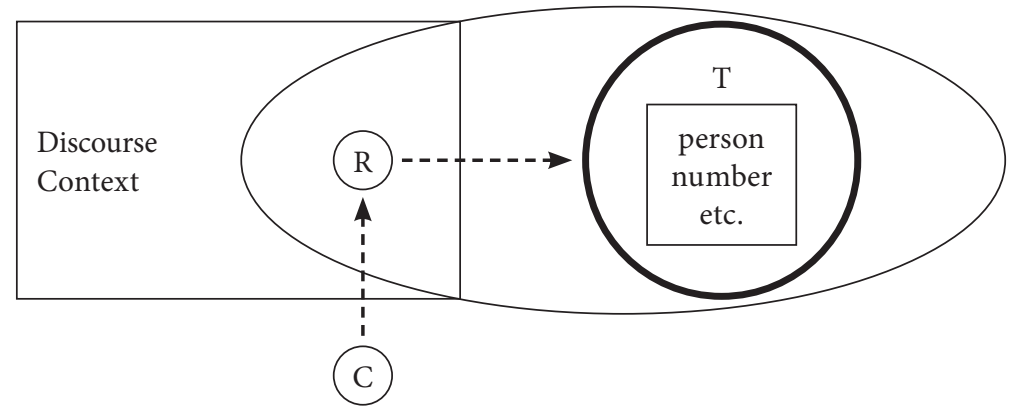

Fig. 1. Pronoun-antecedent configuration

Underlying the configuration in Fig. 1 is the so-called reference point relationship, a mental relationship holding between the conceptualizer, $\mathrm{C}$, and the object of conceptualization, T (target), established via the reference point, R. Specifically, as observed by Langacker (2000: 238) a pronoun, $\mathrm{T}$ (target), which profiles a thing specified for person and number, invokes the appropriate discourse context, equating its profile with a reference point, $\mathrm{R}$, a salient entity of this context. With the dominion, $\mathrm{D}$, established by the reference point, the conceptualizer has access now via the referring expression (i.e. the pronoun $-\mathrm{T}$ ) - to a potential antecedent.

For our analysis to go through it is important to assume that:

i. every nominal can be potentially treated as a reference point, $\mathrm{R}$ (hence become the pronoun's antecedent), where reflexive pronouns are, in contrast to fully fledged noun phrases, markers of what we would like to call high-degree coreference expressions. Reflexives form an accessibility scale - from low accessibility signals like fully fledged noun phrases, to high accessibility units (or high-degree coreference expressions) like personal pronouns, reflexive pronouns or zero anaphors. Following Kemmer (1995: 55), we will define accessibility as "the degree of ease with which a discourse referent [antecedent - H.K.] can be identified or 'picked out' mentally via the use of a given referring element";

ii. accessibility is determined by the intersubjectification process, whereby the lower the accessibility degree of the referring expression, the greater the degree of intersubjectivity is claimed to be involved in the pronoun-antecedent relation. Viewed through the prism of Fig. 1, the lower the values of a referring expression's accessibility, the further away from $\mathrm{T}$ on the R-T axis the reflexive's accessibility value is likely to be located.

iii. the antecedent's accessibility in Polish should be seen in terms of the detransitivization process rather than in terms of the accessibility hierarchy in the sense of Kuno (1987).

In connection with (i), consider the following sentences: 
(22) Orły rodzą orły.

Eagles give birth to eagles.

(i.e. Outstanding individuals beget outstanding offsprings.)

(23) Tom saw an/the elderly, tired man with gray hair in the mirror.

(24) Tom saw himself in the mirror.

(25) Mary went to Warsaw and Peter - to Cracow.

The respective referring expressions in these sentences: orty 'eagles' in the object position in (22), an elderly, tired man with gray hair in (23), himself in (24) and the null element (gap - zero anaphor), left after the deletion of went in (25), represent the varying degrees of accessibility signals in the pronoun-antecedent relationship. Thus whereas himself and the null anaphor in (24) and (25), being high-degree coreference expressions, strongly suggest the presence of a potential antecedent in the discourse (i.e. Tom and went, respectively), the fully fledged noun phrase an elderly, tired man with gray hair only "weakly" points to the antecedent Tom. Notice that (22) does not exhibit even a weak coreference relationship between the two noun phrases: the expression orty in the object can hardly be treated as a referring expression pointing at the (presumed) antecedent orty in the subject position.

Turning to (ii), we need to introduce two important concepts: the idea of subjectification, which we will discuss in the context of so-called viewpoint reflexives, and the concept of intersubjectification, which will be discussed in the context of emphatic reflexives.

\section{Viewpoint reflexives and subjectification}

Consider the following two sentences involving viewpoint point, fist analyzed by Cantrall (1974: 146; adapted):

(26) a. The adults in the picture are facing away from us, with the children placed behind them.

b. The adults in the picture are facing away from us, with the children placed behind themselves.

Although the (a) and (b) sentences of (26) describe a scene in which the adults have their backs turned to an observer of the picture, with the children standing behind them, the reflexive (unlike the pronoun them) is acceptable only under the interpretation that the children stand behind the women as seen from the women's point of view. That is, by uttering (26b) the speaker is watching the scene from the women's vantage point, feeling some sort of empathy with them. Seen from a Cognitive Grammar standpoint, this means that the speaker is on-stage, i.e. he "subjectifies" with his feelings the whole scene involving the women and the children who pose for a photo shoot. This requires a comment.

One of the basic human abilities is subjectification, or virtual motion, a dimension of imagery, i.e. "the construing of the scene in alternate ways" (Langacker 1988: 63). 
Subjectification is a gradual process, where the so-called OVA relation (objective viewing arrangement) between the conceptualizer and the object of his/her conceptualization is replaced, via attenuation, by the EVA relation (egocentric viewing arrangement), as shown in Fig. 2 (Langacker 2000: 298; modified).

Fig. 2(a) represents the OVA configuration: the bold arrow stands for the objective relation which obtains between a trajector such as an agent or an instrument, and the landmark, an entity which could be a patient. $\mathrm{C}$ is the conceptualizer, who is off-stage and who mentally scans the relation between tr and $\mathrm{lm}$. Broken arrows symbolize the process of scanning which takes place in the so-called processing time (T), i.e. the time through which the given conceptualization develops. The broken heavy arrow in Fig. 2(b) symbolizes the attenuation of the OVA relation; the conceptualizer is still scanning the scene, but the relation between tr and $1 \mathrm{~m}$ is motivated to a lesser extent. The objectively existing motivation between $1 \mathrm{~m}$ and $\mathrm{tr}$ disappears in (c), where tr and $\mathrm{lm}$ are linked by the subjective relation, established now by the conceptualizer's mental operations alone. ${ }^{5}$ The virtual (or fictive) movement that takes place here, is, on Langacker's analysis, represented by the movement of the trajector (cf. Langacker 2000: 300):

The (a) and (b) diagrams in Fig. 3 represent the subjectification process seen from the point of view of the mental scanning performed by the conceptualizer. Whereas in (a) the conceptualizer traces the physical motion of, say, the balloon (trajector); in (b), C follows - subjectively - the same path as in (a), locating this time the trajector, say the cliff rising, with respect to a certain reference point $\mathrm{R}$. The scene is construed subjectively in (b) precisely because the conceptualizer assumes the vantage point of $\mathrm{R}$ and, moving along, establishes now - in the absence of any physical movement - the mental link alone between $\mathrm{lm}$ and tr.

This brings us to the emphatic reflexives and associated with them, the intersubjectification process.

\section{Emphatic reflexives and intersubjectification}

As already remarked, all reflexive pronouns are markers of high coreference in a discourse, signaling the presence of a potential antecedent; for Kemmer (1995), they are "unexpected" as discourse roles. This is especially true in the case of the emphatic-self, in which case, according to Kemmer (1995: 57):

To illustrate, the (a) example below is an OVA configuration, whereas (b) represents the EVA relationship.

a. The balloon is rising up to three thousand feet.

b. The cliff is rising two hundred feet high above the lake level.

In (a) the movement is real: the conceptualizer is following the movement of the balloon rising. In (b) the movement is virtual: it is not the cliff that is moving up high, but rather the conceptualizer is "moving mentally" along the ridges of the cliff. 


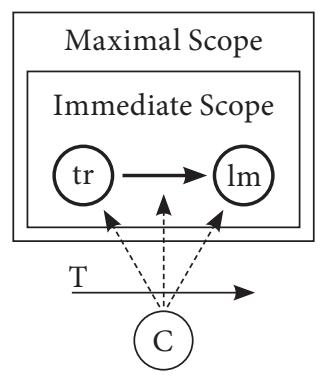

a. Initial Configuration

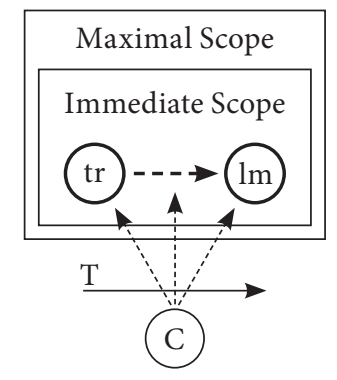

b. Attenuation

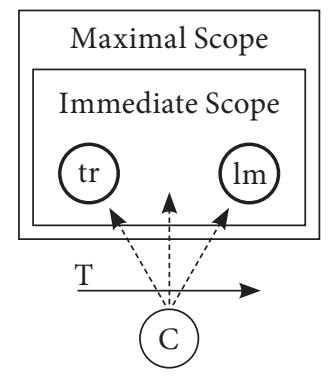

c. Subjectification

Fig. 2. Subjectification

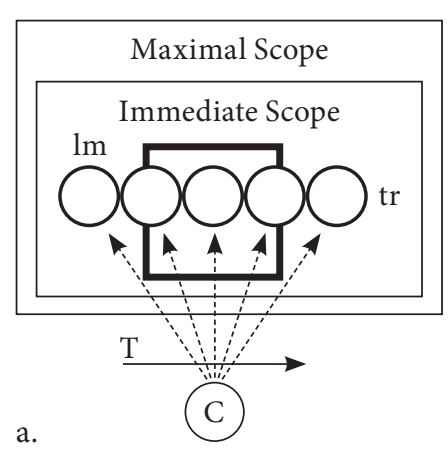

Fig. 3. Subjectification as TR-movement

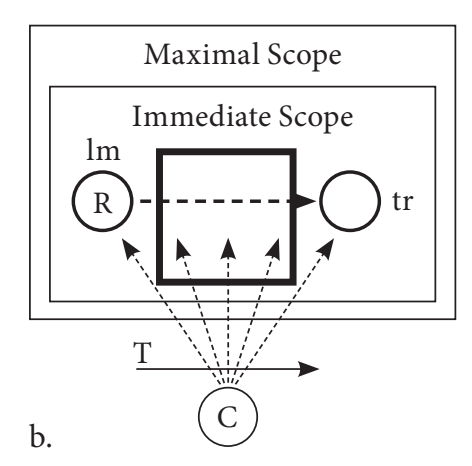

b.

it is necessary to consider the meaning of emphatic -self in terms of the relation of its referent to speaker expectations. In most general terms, emphatic -self is a signal that the discourse referent indicated by -self is a referent that is to some degree unexpected in the discourse role or clausal role where it occurs. In other words, some other potential referent or referents might have, for whatever reason, been more likely or expected. The -self form functions, in fact, to exclude any alternative potential referents that might have been expected to occur instead of the one the self-marked noun phrase refers to.

Seen in discursive terms, the role of the emphatic-self, Kemmer observes, is to identify recurrent discourse patterns, the most important of which is the topic pattern, represented by a formula: Topic $\rightarrow$ shift of topic to associated entity $\rightarrow$ unexpected shift back to topic, where " $\rightarrow$ " stands for temporal sequence. The topic pattern, Kemmer further notes, following Langacker (1993), can readily be recast in terms of the reference point relationship, "a conceptualisation used as a way of accessing other conceptualisations" (Kemmer 1995: 58). As an example illustrating the above topic pattern formula Kemmer offers the following piece of narration from the New York Times Magazine (Kemmer 1995: 58): 
(several leading figures were revealed as Stasi agents)

Chief among them was Sacha Anderson, an ultra-hip writer, publisher, ceramic designer and musician. Revelations about the extent of his betrayals have astonished and enraged many of the people who lived and worked with him.

A strange day in Berlin: I spent the morning with one of the people Anderson spied on, the writer Lutz Rathenow, and the afternoon with Anderson himself. [The article goes on to describe both meetings.] (NY Times Magazine, 12 April 1992: 50)

Notice that, in accordance with the topic pattern formula, Anderson is introduced first as a local topic. Then attention is shifted to Rathenow and others, who had been spied on by Anderson; Anderson functions as a reference point for all these individuals. Then the emphatic himself appears, excluding "the others" and thus pushing the discourse back to Anderson, the reference point of the local discourse.

The question now is this: How can the discourse-governed emphatic-antecedent relationship be accounted for in the Cognitive Grammar model? In order to answer this question we have to introduce the notion of the Current Discourse Space and the mind reading strategy.

First, we have to define the term "intersubjectivity" itself. Zlatev et al. (2008: 3) offer the following characteristic of intersubjectivity:

i. human beings are primordially connected in their subjectivity, rather than functioning as monads who need to "infer" that others are also endowed with experiences and mentalities that are similar to their own;

ii. the sharing of experiences is not only, not even primarily, on a cognitive level, but also (and more basically) on the level of affect, perceptual processes and conative (action-oriented) engagements;

iii. such sharing and understanding is based on embodied interaction (e.g. empathic perception, imitation, gesture and practical collaboration);

iv. crucial cognitive capacities are initially social and interactional and are only later understood in private or representational terms.

As put succinctly by Rembowska-Płuciennik (2012: 107), subjectivity is "the ability to think about the reasoning of others as well as the ability to mentally represent the current, recollected as well as a fictitious state of someone else's mind", ${ }^{6}$ where "thinking about the reasoning of others" involves what is known in cognitive psychology and philosophy under the term of mind-reading. The idea of mind reading, which is referred to by Langacker as "the apprehension of other minds", can be presented as in Fig. 4 (Langacker 2007: 183; modified).

$\mathrm{S}$ symbolizes speaker, $\mathrm{H}$ stands for hearer and $\mathrm{G}$ for the ground. In the case of the discourse participants' mind integration, the speaker and the hearer switch roles. In one speech event, represented by Input Space 1, the speaker (S) addresses the hearer $(\mathrm{H})$; in the other speech event, represented by Input Space 2, it is the hearer that addresses the speaker. The blend represents the canonical speech event scenario, where the

\footnotetext{
6 The translations from the Polish is mine.
} 


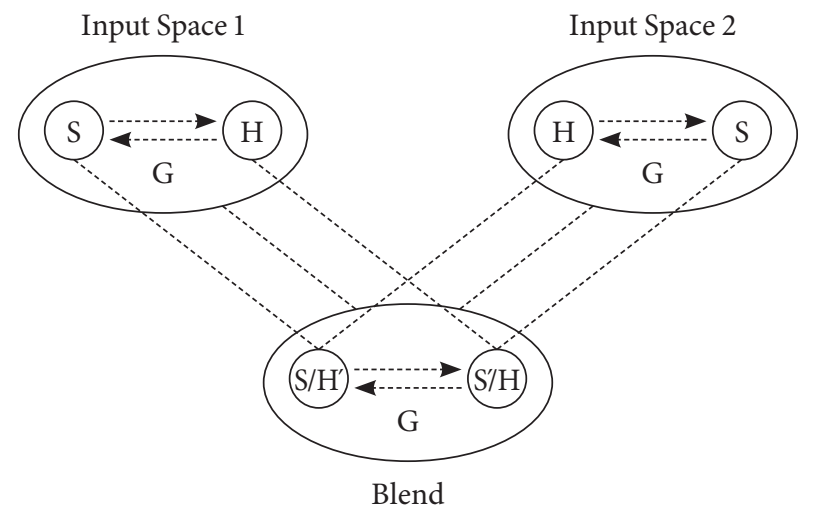

Fig. 4. The apprehension of other minds (mind reading)

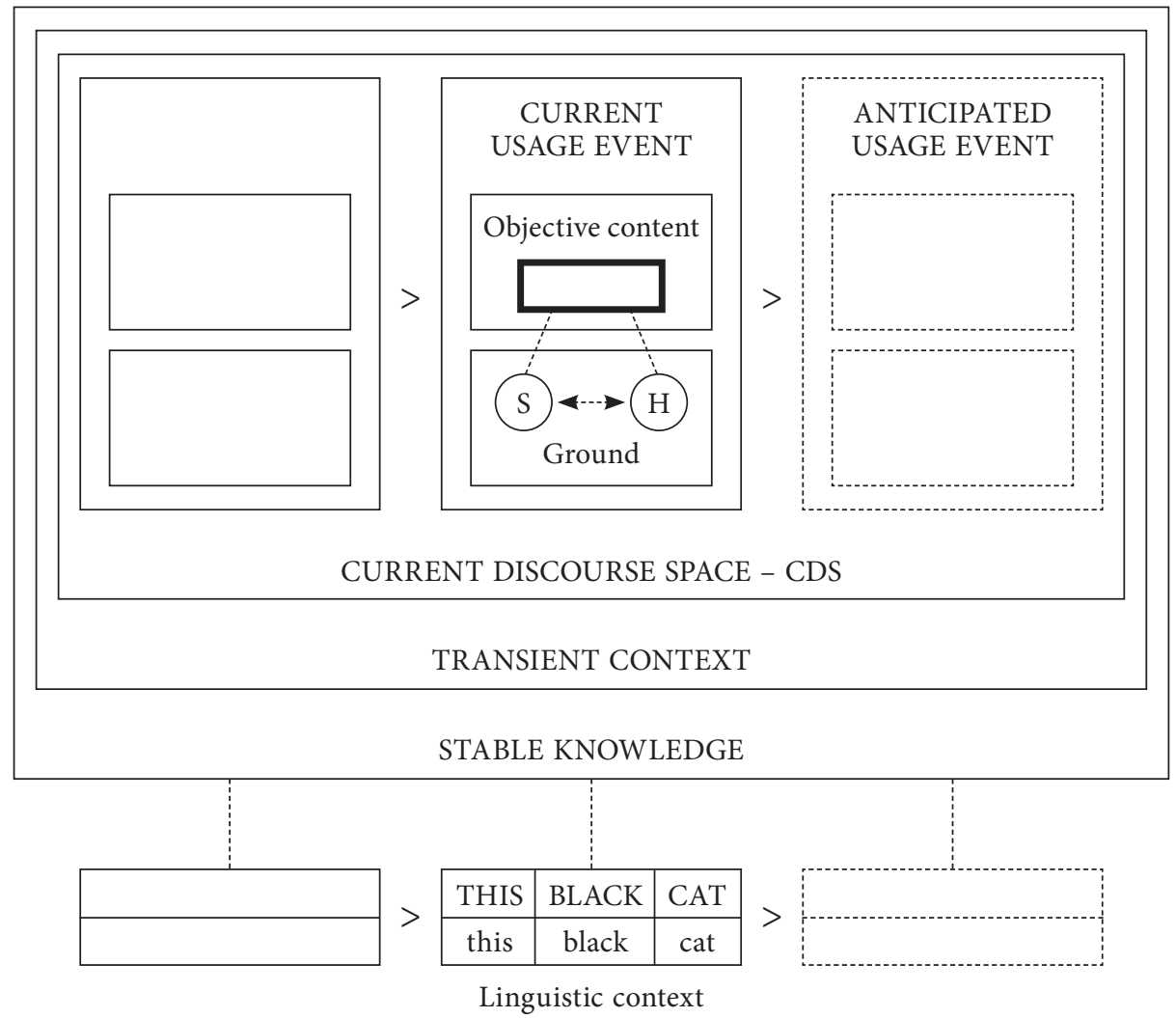

Fig. 5. The Current Discourse Space (modified) 
roles of the discourse participants overlap: the current speaker $(\mathrm{S})$ is also the potential addressee $\left(\mathrm{H}^{\prime}\right)$, while the current addressee $(\mathrm{H})$ is also the potential speaker $\left(\mathrm{S}^{\prime}\right)$.

It should be obvious now that mind integration plays a crucial role in the management of contextual knowledge by the discourse participants in their interpretation of words, sentences, and larger portions of linguistic structure, as it is context that provides "additional aspects" of linguistic meaning. In particular, when engaged in verbal interaction with the addressee, the speaker establishes with the latter the common interpretational basis of what is being said, including the Current Discourse Space (CDS), from which all expressions are abstracted. The CDS can be presented as in Fig. 5 (Langacker 2008: 466; modified).

The diagram, which is a modified version of Langacker's representation of the usage event, depicts a "discursive transaction" between $\mathrm{S}$ and $\mathrm{H}$, a context-based "common interpretational basis" (Langacker 2008: 466). This common interpretational basic includes the CDS (upper box in the diagram) and the "negotiated" meaning of a linguistic expression (here: the black cat; lower box). The CDS consists of three basic elements: the current usage event, the previous usage event, and a usage event that can be anticipated. This arrangement holds at all "levels" of conceptual organization, including all linguistic "levels". Thus, according to Langacker, expressions such as thus, therefore, this being the case, etc. point to the presence of a previous usage event, whereas expressions such as, say, if, when, etc., because they induce expectations, are to be taken to signal the existence of anticipated usage events. The current usage event consists of so-called objective content (OC), i.e. the situation or a thing conceptualized that is communicated between the speaker (S) and the hearer $(\mathrm{H}) . \mathrm{S}$ and $\mathrm{H}$ form what is called the ground, i.e. persons and circumstances accompanying the production and understanding of utterances.

Now, we wish to claim that the "intersubjective negotiation" of meaning between the speaker and the hearer - of what has been said - takes place in the CDS, as presented diagrammatically in Fig. $6{ }^{7}$

Figure 6 presents the conceptual integration-based negotiation of meaning between the speaker and the hearer in discourse. Based on the analysis of a sentence or a text, which is the objective content of the CDS (cf. Fig. 5), the speaker and the hearer each evoke their own input space (in order to "apprehend each other's mind") and arrive - during the meaning negotiation process - at the common interpretation of what the subject of their discursive exchange is. It is precisely this kind of negotiation, we would like to claim now, that is involved in all aspects of language use, including the establishment by the conceptualizer of the (degree of) antecedents' accessibility

Because the term "conceptualizer" is used by Langacker with reference to both the speaker and the hearer, we can avoid answering here the otherwise important question: "Who does the speaking and who does the listening". Still, toutes proportions gardées, one can draw interesting parallells between the way a literary text is read by the reader and the strategy of linking a reflexive with its antecedent. In the case of a literary text the reader intersubjectifies the text by "entering into a dialogue with it (and ultimately, with the author; see a discussion in Kardela, Kędra-Kardela 2014); in the case of the reflexive-antecedent relation, a similar intervention takes place: the conceptualizer while scanning the text isolates an NP which is likely to become the antecedent for the reflexive. 


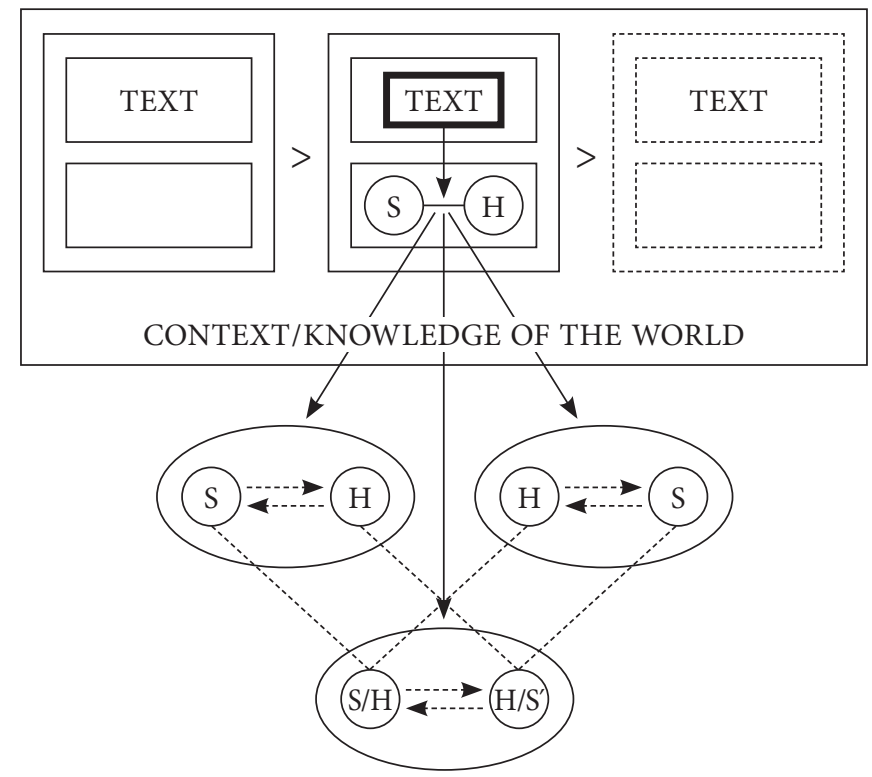

Fig. 6. The intersubjective negotiation of meaning

for reflexives. In what follows we will formulate the accessibility parameters for the reflexive-antecedent relation integrating them with the general reference point configuration for reflexives.

\section{The accessibility parameters for reflexives}

In Section 3 we noted that the degree of antecedents' accessibility for reflexives is determined by the intersubjectification process, whereby the lower the accessibility degree the referring expression displays, the greater the degree of intersubjectivity is judged to be involved in the pronoun-antecedent relation. In particular, we formulated a generalization according to which the lower the values of the accessibility degree an expression has, the further away from $\mathrm{T}$ on the R-T axis in Fig. 1 the accessibility value for the reflexive will be located. In what follows we formulate a number of parameters for reflexives which will help "gauge" the distance between $\mathrm{R}$ and $\mathrm{T}$ on the R-T axis.

Let us start with English reflexives. Suppose that these referring expressions do indeed signal the existence of the reference point configuration which underlies the reflexive-antecedent relationship. Suppose further that this relationship, expressed on the R-T axis in Fig. 1, exhibits prototype effects in the sense of Lakoff (1987) in that the particular instance of the reflexive can be seen to be located nearer or farther away from $\mathrm{T}$, in accordance with the accessibility scale. The scale involves two different yet closely related sub-scales: a syntactic and a semantic scale. The accessibility 
scale for the English reflexives might look as follows (based on Kuno 1987; after Deane 1992: 206-207):

(27) The accessibility scale for English reflexives:

i. Syntactic Scale: The accessibility of the subject of a verb for a reflexive varies in strength according to the syntactic role of the anaphor, and is:

Strongest: the verb's direct object anaphor: John washed himself; John bought himself a new jacket;

Middle: object of a preposition anaphors, e.g. John talked to Greg about himself;

Weakest: picture nouns (and generally, long distance reflexives), e.g. A picture of himself hanging on the wall is believed by Mary to frighten Tom.

ii. Semantic scale: The accessibility of the subject of a verb for a reflexive varies in strength according to the semantic/discourse nature of the reflexive, and is:

Strongest: Definite animate NP, e.g. John washed himself;

Middle: Definite inanimate NP (cf. Fiengo 1980: 52), e.g. That clay tablet deciphered itself; The gears on this bicycle shift themselves; Foreign cars sell themselves;

Weakest: indefinite pronouns (everybody, nobody, somebody), e.g. Somebody hasn't shaved himself today, eh? (X reproaches Y for not having shaved himself); viewpoint reflexives, e.g. Near himself, John saw a big spider.

Turning to Polish, we propose to define accessibility not in terms of the "accessibility of a subject of a verb", as stated in the above scale for the English reflexives, but in terms of the degree of detransitivization as signaled by the presence of the reflexive siebie/sie form in the sentence/text. The reason for this is that Polish (i) makes extensive use of the clitic sie rather than siebie, replacing the latter in the direct object position in a sentence, ${ }^{8}$ and (ii) the reflexive się is associated with a number of $s e$ mantic phenomena linked with transitivity relations such as reciprocality, ergativity or absolute construal in the sense of Langacker (1991).

We can define ditransitivization as a process in which a transitive construction loses its "transitive qualities". As already remarked, among the markers signaling such a process are the reflexive siebie and its cliticized variant sie. ${ }^{9}$ The ditransitivization process is subject to the Transitivity Hierarchy, which can be formulated as follows (based on Maldonado 1992: 63):

(28) The Transitivity Hierarchy

transitive $>$ reciprocal $>\left\langle\begin{array}{l}\text { reflexive-siebie } \\ \text { reflexive-się }>\text { ergative }>\text { middle }>\text { absolute }^{10}\end{array}\right.$

8 Thus it is more appropriate to say in Polish Jan umyt się rather than Jan umyt siebie 'John washed himself', although when used in the Dative, only the reflexive siebie can be used: Jan kupit sobie /*się/ płaszcz 'John bought himself a jacket'.

9 The role of the emphatic sam is different. Like the emphatic -self in English, sam is associated with the topic and the topic shift, hence not subject to the Transitivity Hierarchy. 
The hierarchy accounts for the degree of transitivity a particular sentence displays in relation to a fully transitive construction, where a prototypical transitive construction can be defined as follows (cf. Taylor 1995: 206-207; adapted):

(29) The prototypical transitive construction

i. The construction describes events involving two, and only two participants, encoded by the subject and direct object Nps, respectively;

ii. The two participants are highly individuated, i.e. they are discrete, specific entities [...] distinct both from each other, and from the background environment;

iii. The event is initiated by the referent of the subject NP, i.e. by the agent. [...] the subject NP is the sentence topic [...];

iv. The agent acts consciously and volitionally, and thus controls the event [...] the agent is typically a human being;

v. As a consequence of the agent's action, something happens to the patient, i.e. the referent of the object NP [...];

vi. After the occurrence of the event, the patient is in a different state from before the event [...];

vii. [According to Givón (1993, 2: 46), the verb of the prototypical transitive clause codes an event that is compact (non-durative), bounding (non-lingering), sequential (non-perfect), and realis (non-hypothetical). The prototypical is thus a fast-paced, completed, real and or/cognitively salient change - H.K.];

viii. The event has a causative component - the agent's action causes the patient to undergo a change;

ix. Typically, agent and patient are not only clearly differentiated entities; often they also stand in an adversative relationship.

Consider the following examples:

(30) Janek uszkodził rower Piotrka. (transitive)

John damaged Peter's bike.

(31) Kibice bili się. (reciprocal).

The football fans beat each other bloody.

(32) Jan umył się. (reflexive)

John washed himself.

(33) Drzwi otworzyły się. (ergative)

The door opened.

10 In Ronald Langacker's model of Cognitive Grammar, an event can be viewed from two perspectives: from the energetic chain perspective (or force dynamics perspective) and from the absolute (or zero construal) standpoint. While under the force dynamics construal, an event is seen as involving the flow of energy being transmitted from one participant (Agent) to another participant (Patient) (Langacker 1991: 283), under the absolute construal, no causer of the event is absent and the event "just unfolds" (see a discussion in Langacker 1991; also Kardela 2000). 
(34) Te pomidory dobrze się sprzedają. (middle)

These tomatoes sell well.

(35) Jan się długo namyślał. (absolute)

John was brooding (what to do).

The most prototypical instance of the transitive construction is (30), which satisfies all the conditions stated in (29); it also occupies the highest position in the Transitivity Hierarchy as stated in (28). Less prototypical is (31), which does not satisfy condition (29vii), because in this case, the clitic sie "weakens", to use Barbara Dancygier's (1997: 313) wording, "the salience of the distinction between the semantic roles". The least prototypical construction is (35), which meets none of the conditions specified in (29) and is localized at the very end of the Transitivity Hierarchy.

\section{Putting it all together: Reference point again}

We can present now a unitary account of reflexives in Polish and English based on the combined ideas of reference point and intersubjectification-driven negotiation of meaning. Consider the diagram in Fig. 7.

The diagram shows the accessibility values for English and Polish reflexives on the R-T axis of the reference point relationship, established as a result of the intersubjectification process operating on the reflexive-antecedent configuration. Whereas the values closer to $\mathrm{T}$ are associated with a lesser degree of the conceptualizer's intersubjectivity, the values closer to R involve a greater degree of the conceptualizer's mental effort in following the R-T path, hence they display a higher degree of intersubjectivity. Consider first (46) and (47). The accessibility values for the respective reflexives are very high here: the accessibility value of siebie in (46) is high on the Transitivity Hierarchy and so is the accessibility value for himself on the Accessibility Scale of (27). (Note that himself is the verb's direct object anaphor and its possible antecedent is a definite animate NP.) Equally strong accessibility values should be attributed to the emphatics sam in (44) and to myself in (45), which, as already stated, are associated with discourse-related topicalization, and to the picture noun, a picture of himself in (43), which, effectively, possesses all the features of an English emphatic-self. Next come the reflexives in (41) and (42). Notice that the reflexive himself in (42) is a prepositional object anaphor (and not a direct object anaphor), hence its accessibility value, as evidenced by the ambiguity of the sentence, should be judged to be relatively low. A relatively low accessibility value should also be attributed to the reflexive sobie in (41). Because the sentence Ola kazała Janowi kupić sobie płaszcz codes two events, associated with the verb kazać 'tell, ask' and the verb kupić 'buy', the Transitivity Hierarchy, which is valid for a simple sentence only, does not apply in this case. This being so, the disambiguation will therefore require a great degree of "intersubjective intervention" on the part of the conceptualizer. Still lower accessibility values have the reflexives sie in (40) and himself in (39). In (40), the understood subject "you" is a very weakly individuated 


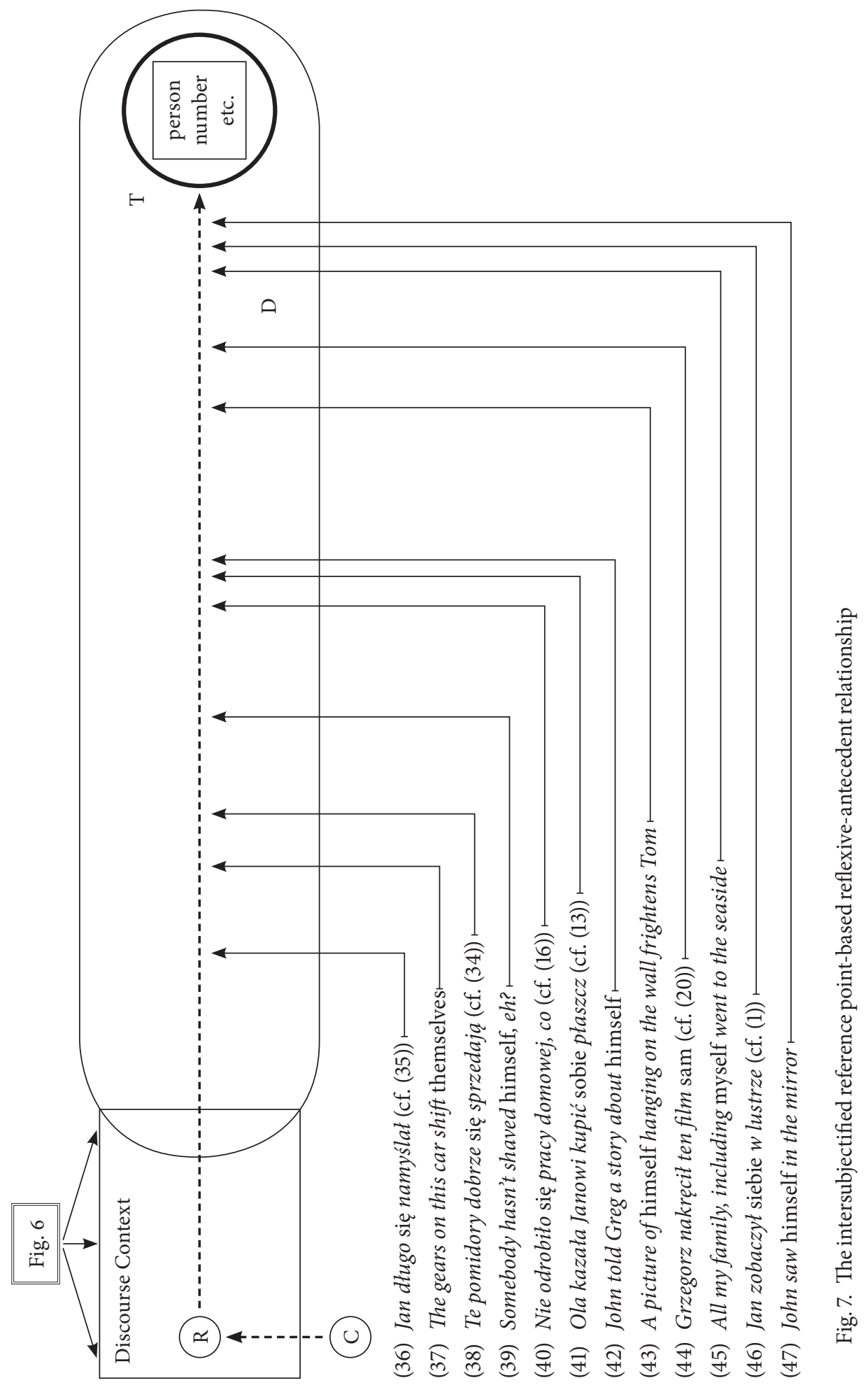


participant (cf. (29ii)): it can only be inferred from the discursive context; in (39), a likely antecedent for himself is somebody, which has the weakest accessibility on the semantic scale of (27ii). The examples in (36) and (37) are middle voice constructions: the English reflexive themselves in (37) has the definite inanimate subject as its potential antecedent, hence its relatively low accessibility value. The accessibility value for the reflexive sie in (38) is equally low, as in this case the reflexive is a Middle Voice marker. Finally, we have (36), in which się marks the absolute construal of the event coded by the sentence.

\section{Conclusion}

Our discussion can be summarized in points as follows:

i. Reflexives form an accessibility scale - from low accessibility signals to high accessibility units, depending on how much mental effort is required for a conceptualizer to identify a discourse referent (antecedent);

ii. Accessibility is defined by the intersubjectification process, whereby the lower the accessibility of the referring expression (i.e. reflexive) is, the greater the degree of intersubjectivity is held to be involved in the pronoun-antecedent relation;

iii. While in English the accessibility is defined in terms of the "accessibility of a subject of a verb", in Polish, the degree of the antecedent's accessibility should be seen in terms of the detransitivization process which affects the reflexiveantecedent configuration.

\section{References}

Cantrall W. 1974. Viewpoint, reflexives, and the nature of noun phrases. The Hague.

Chomsky N. 1973. Conditions on transformations. - Anderson S., Kiparsky P. (eds.). Festschrift for Morris Halle. New York: 232-286.

Dancygier B. 1997. Reflexive markers in Polish. Participants, metaphors and constructions. Marjolijn V., Dong Lee K., Sweetser E. (eds.). Lexical and syntactical constructions and the construction of meaning. Amsterdam, Philadelphia: 311-328.

Deane P. 1992. Grammar in mind and brain. Explorations in cognitive syntax. Berlin, New York.

Drogosz A. 2008. Reflexivization in English and Polish. A cognitive grammar approach. Olsztyn.

Fiengo R. 1980. Surface structure. The interface of autonomous components. Harvard (Mass.).

Givón T. 1993. Topic continuity in discourse: A quantitative cross-language studies. Amsterdam, Philadelphia.

Helke M. 1971. The Grammar of English reflexives. [Ph.D. Diss.]. Cambridge (Mass.).

Jackendoff R. 1972. Semantic interpretation in generative grammar. Cambridge (Mass.).

Kański Z. 1986. Arbitrary reference and reflexivity: A generative study of the Polish pronoun "się" and its English equivalents. Katowice.

Kardela H. 1985. A grammar of English and Polish reflexives. Lublin.

Kardela H. 2000. Dimensions and parameters in grammar. Studies on A/D asymmetries and subjectivity relations in Polish. Lublin. 
Kardela H., Kędra-Kardela A. 2014. Enter the author: A cognitive analysis of literary communication. - Babilas D., Piskorska A., Rutkowski P. (eds.). Face to face, page to page. PASE papers in literature, language and culture. Warszawa: 439-452.

Kemmer S. 1995. Emphatic and reflexive -self: expectations, viewpoint, and subjectivity. Stein D., Wright S. (eds.). Subjectivity and subjectivisation. Cambridge: 53-82.

Kubiński W. 1987. Reflexivisation in English and Polish. An arc pair grammar analysis. Tübingen.

Kuno S. 1987. Functional syntax: Anaphora, discourse and empathy. Chicago.

Lakoff G. 1987. Women, fire and dangerous things. What categories reveal about the mind. Chicago.

Langacker R. 1988. A view of linguistic semantics. - Rudzka-Ostyn B. (ed.). Topics in cognitive linguistics. Amsterdam, Philadelphia: 48-90.

Langacker R. 1991. Cognitive grammar. [vol. 1]. Descriptive application. Stanford.

Langacker R. 1993. Reference point constructions. - Cognitive Linguistics 4: 1-38.

Langacker R. 2000. Grammar and conceptualization. Berlin, New York.

Langacker R. 2007. Constructing the meanings of personal pronouns. - Radden G., Köpcke K.-M., Berg T., Siemund P. (eds.). Aspects of meaning construction. Amsterdam, Philadelphia: 171-187.

Langacker R. 2008. Cognitive grammar. A basic introduction. Oxford.

Leskosky R. 1972. Intensive reflexives. - Green G. (ed.). Studies in the linguistic sciences 2.1. Urbana-Champaign: 42-65.

Maldonado R. 1992. Middle voice. The case of Spanish 'se'. [Ph.D. Diss.]. San Diego.

Postal P. 1971. The cross-over phenomena. New York.

Postal P. 1974. On raising. One rule of English grammar and its theoretical implications. Cambridge (Mass.).

Rembowska-Płuciennik M. 2012. Poetyka intersubiektywności. Kognitywistyczna teoria narracji a proza XX wieku. Toruń.

Szlifersztejnowa S. 1968. Bierne czasowniki zaimkowe/reflexiva/ w języku polskim. Wrocław.

Szymańska I. 2000. A construction grammar account of the reflexive się in Polish. [Ph.D. Diss.]. Warszawa.

Taylor J. 1995. Linguistic categorization. Prototypes in linguistic theory. Oxford.

Verheijen R. 1983. Reflexives and intensifiers in Modern British English. [Ph.D. Diss.]. Leiden. Warshawsky-Harris F. 1965. Reflexivization I and II. Bloomington.

Wilczewska K. 1966. Czasowniki zwrotne we współczesnej polszczyźnie. Toruń.

Zlatev J., Racine T., Sinha Ch., Itkonen E. (eds.). 2008. The shared mind. Perspectives on intersubjectivity. Amsterdam, Philadelphia. 